\title{
The measurement of human oral forces*
}

\author{
JOHN D. RUGH \\ University of California, Santa Barbara, California 93106 \\ and \\ WILLIAM K. SOLBERG \\ School of Dentistry \\ University of California, Los Angeles, California 90024
}

This paper reviews the types of instruments used and problems encountered in the measurement of human biting forces. A new instrument, developed for this purpose, which employs strain gauges mounted on a cantilever bridge bite element is described. Associated circuitry, which includes a Wheatstone bridge, amplifier, and integrator, is described. The integrator enables the investigator to record accumulative force over time. Biting force values recorded at five different areas of the mouth are presented from 11 male and 8 female Ss.

Several techniques have been described for the measurement of human biting forces. The instruments developed for this purpose have been referred to as gnathodynamometers (gnatho from Greek, meaning jaw). This paper reviews the types of instruments developed to date and describes a recently developed instrument which overcomes many of the problems found in earlier gnathodynamometers.

The earliest, and perhaps most novel, method employed to determine maximum human biting forces was that of J. R. Patrick (see Klaffenbach, 1936 ) in the early 1890 s. The average force required to crush several different types and sizes of nuts was determined by the use of a "crushing machine." Estimates of biting forces were then made after human Ss attempted to crush different sizes and types of nuts between their teeth.

Black (1895) and Johnson and Hatfield (1917) developed gnathodynamometers which mechanically indexed the bending of spring steel arms which were bit upon by the Ss (see illustration in Fig. 1). However, several problems associated with their usage were noted. Black recognized that biting forces depended upon the vertical separation of the teeth and reasoned that full muscle force could not be exerted with the mouth open widely. He also reported difficulty in keeping the bite pads thin, yet strong enough to prevent breakage. A bite block thickness of $18 \mathrm{~mm}$ was required to prevent breakage. [The ideal bite plate thickness for measurement of biting forces has yet to be determined. The

*The development of this apparatus was supported by USPHS Grant 5-S01-RR-5304. The authors would like to acknowledge the assistance of Allan Leon and Joel Brodsky in collecting data and calibration of the instrument. We wish to thank $R$. J. Schnell, School of Dentistry, University of Indiana, who was particularly helpful in supplying published and unpublished review materials. force capabilities. The exact positioning of the bite pads between the teeth was also found to influence force measures due to different leverages at the extremities of the bite plate.

An apparatus developed by Boos (1940) overcame many of the above problems but was usable only with Ss having full upper and lower dentures. Major advances in gnathodynamometer designs were made as variable inductance and wire strain gauges became available. Howell and Manly (1948) developed a variable inductance-type strain gauge (Fig. 1) with interchangeable bite plate elements; these allowed changes in vertical dimension to be made and a wide range of forces to be measured. Biting forces applied to the spring steel plate moved a silver foil near a small inductance coil, thus varying the inductance of the coil. A grid dip meter-type circuit converted the variation in inductance to a dc current which was used to indicate biting force. The thickness of the bite element was reported to be $6 \mathrm{~mm}$ before adding cushioning materials. The same principles were employed in the design of a small gnathodynamometer, developed by Howell and Brudevold (1950), which was inserted under an artificial tooth. This instrument allowed investigators to record force information without interfering with normal chewing. Strain gauges installed on cantilever
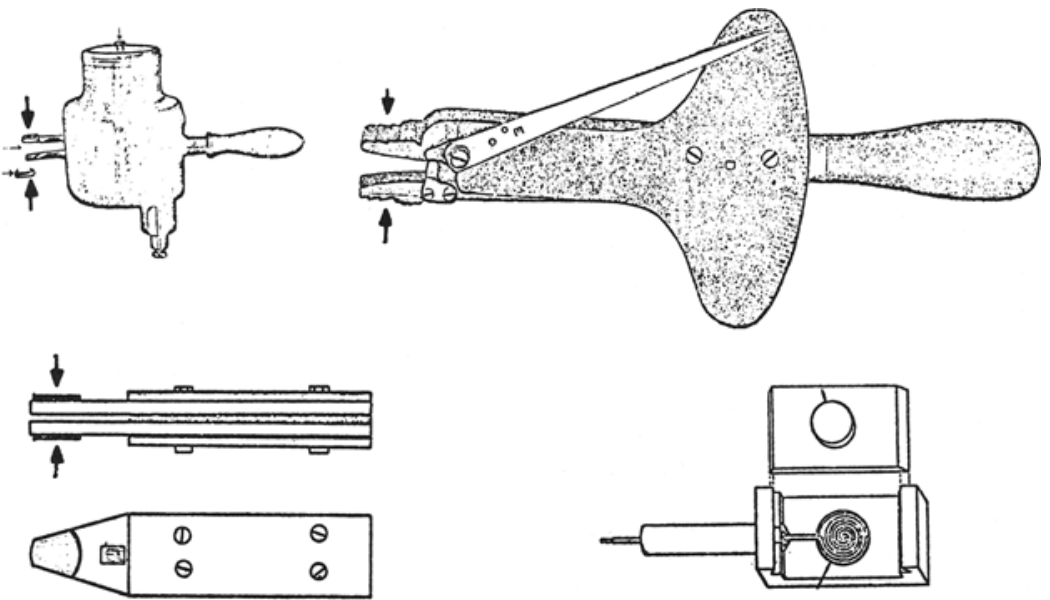

Fig. 1. Four gnathodynamometer types developed to measure human biting force. The upper left-hand instrument was employed by Johnson and Hatfield (1917). Black's 1895 gnathodynamometer is pictured in the upper right-hand corner. A cantilever beam type of instrument employed by several investigators is diagrammed in the lower left-hand corner. Arrows point to the bite pads on each of these instruments. Howell and Manly's (1948) variable inductance strain gauge gnathodynamometer is diagrammed in the lower right-hand corner. The spring plate with bite button is inserted into the grooves in the inductor housing. Biting force is applied directly on top of the inductance coil. The gnathody namometers are not pictured to actual scale. 


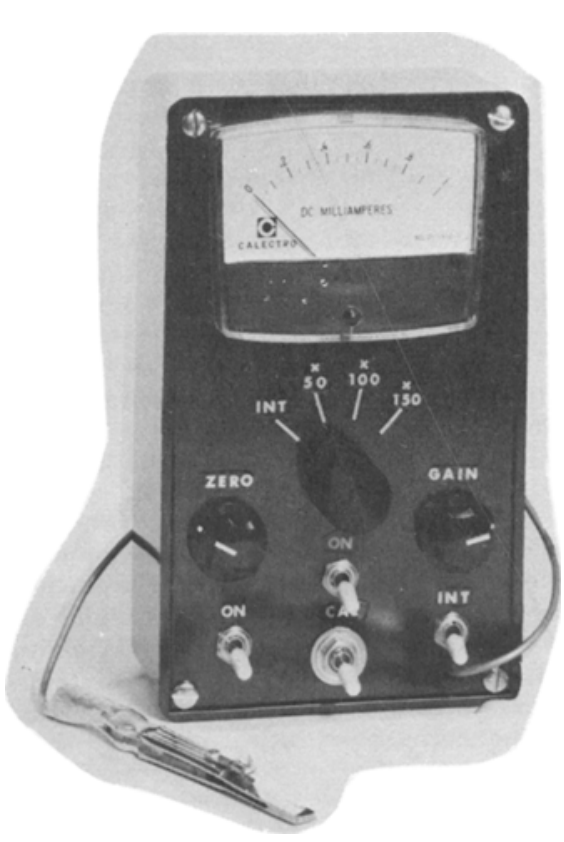

Fig. 2. Portable gnathodynamometer. See text for construction and operating details.

beam arrangements (Fig. 1) have been successfully employed by several in vestigators (Boone, 1962; Vail, 1970; Bowman, 1970); however, the construction details of these instruments are not readily available.

More recently, small strain gauges have been mounted within a single tooth. Anderson (1956) described an apparatus and procedure for measuring whole-tooth loads using strain gauges mounted within the tooth where previous restorations had been made. Scott and Ash (1970) have reported the development of a small transmitter the size of a molar tooth crown which transmits information from eight sensors mounted within the occlusal surface of an artificial molar tooth.

For purposes of our research, a gnathodynamometer with an extremely thin bite plate was required. We needed a device which could be used with Ss having natural dentition and which did not require modification of the existing dentition. The within-tooth or under-tooth techniques (Howell \& Brudevold, 1950; Anderson, 1956; Scott \& Ash, 1970) appeared ideal in that they require the least vertical separation of the teeth; however, they require considerable time and skill to install and generally require modification of the dentition. Other gnathodynamometers have bite blocks requiring a vertical separation in excess of $6 \mathrm{~mm}$. Attempts in our laboratory to reduce the thickness of the bite pads on cantilever beam-type gnathodynamometers to less than $6 \mathrm{~mm}$ were unsuccessful. A cantilever bridge design, however, was found to work well with two thin (1-mm) beams.

The instrument (Fig. 2) described below consists of a cantilever bridge and strain gauge arrangement with a bite plate thickness of $2.5 \mathrm{~mm}$ prior to cushioning. Associated circuitry, consisting of a Wheatstone bridge, dc amplifier, and meter, is described. Also described is an integrator circuit which allows the measurement of accumulative force over time.

\section{APPARATUS}

Bite Plate Element

Construction of the bite element was simplified by using Sklar Model 160-135 forceps (38-04 Woodside Avenue, Long Island City, New York), modified to form a dual cantilever bridge arrangement (Fig. 3). A fulcrum was added, and the forceps points were rounded and permanently closed with a screw and nut. Small strain gauges were mounted using Eastman 910 cement (BLH Electronics, Inc., Waltham, Mass.) to both sides of one of the forceps' handles (Fig. 3). The two gauges form two legs of a Wheatstone bridge (Fig. 4). Employing the gauges in this manner doubles the gauge factor and provides temperature compensation. A positioning arm was attached to and protruded from the focal point wedge screw. This positioning arm was found useful in replicating the exact placement of the bite element in the mouth, thus assuring that the biting force occurred at the same location on repeated measurements. Several bite plate cushioning materials were examined and rejected. It was found that most common plastic and rubber materials were inadequate, as they were too
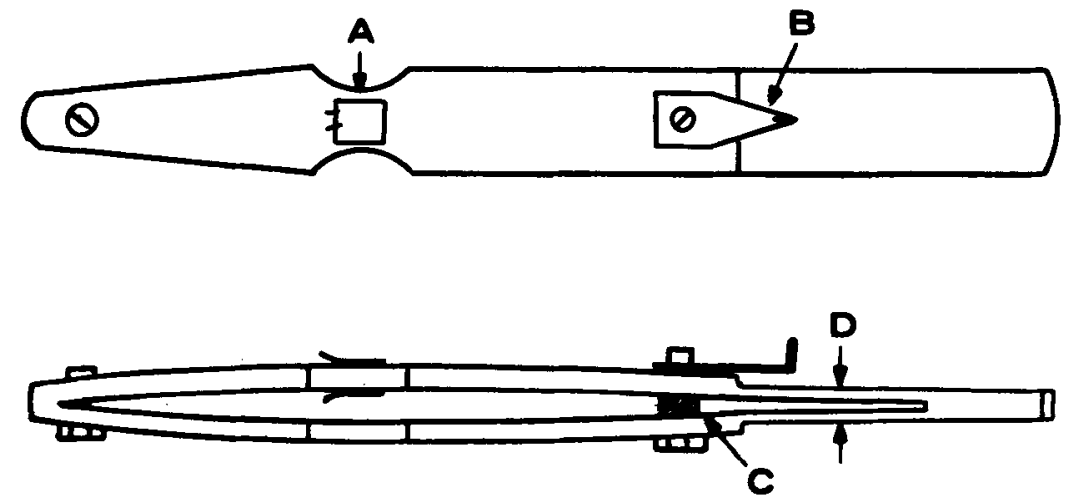

Fig. 3. Detailed drawings of dual cantilever bridge bite element. Two strain gauges are mounted on either side of the forcep's handle, which was reduced in width at Point A. A positioning arm (Point B) protrudes toward the bite surface (Point D). A wedge mounted at Point $C$ works as a fulcrum. Force applied at Point $D$ is transferred to Point $A$ and sensed by the two strain gauges. A three-wire shielded cable connected the two strain gauges to the Wheatstone bridge and amplifier network. 


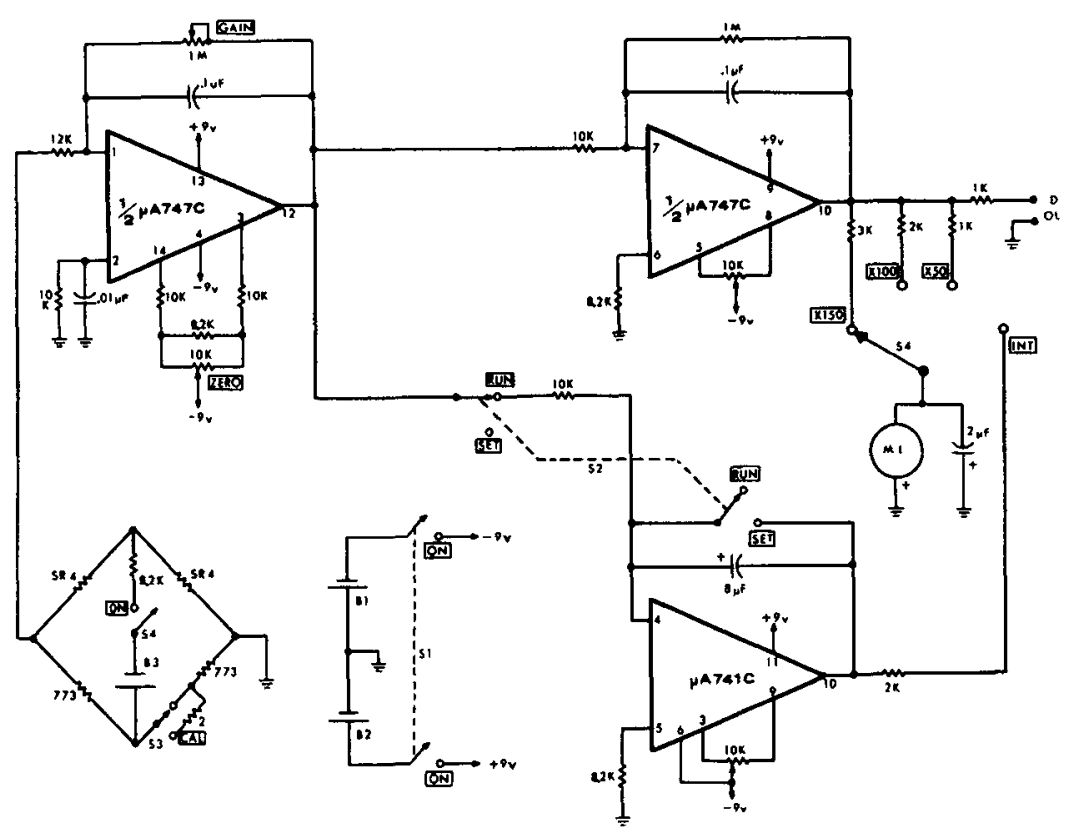

Fig. 4. Circuit diagram of gnathodynamometer. The two Type FAE-06N-1256EL (SR-4) strain gauges (BLH Electronics, Waltham, Mass. 02154 ) are mounted on the bite element. The dual 747 operational amplifier may be replaced with two 741 amplifiers. Batteries $\mathrm{B1}, \mathrm{B2}$, and $\mathrm{B3}$ are 9-V transistor radio batteries (Eveready No. 216). Meter M1 is a Caletro No. D1-912 milliammeter. Resistance values are shown in ohms except where noted. The 773 $\pm 1 \%$ resistors in the bridge network may be replaced by other paired precision resistors ranging from 100 to $1,000 \mathrm{ohms}$. Boxed lettering indicates front panel controls.

network, including a 2-ohm calibration resistor and switch (lower left-hand corner, Fig. 4), fed into a high gain inverting operational amplifier. The $10 \mathrm{k}-\mathrm{ohm}$ dc offset potentiometer is used to compensate for slight imbalances in the Wheatstone bridge and serves as the meter zero control. An $8.2 \mathrm{k}-\mathrm{ohm}$ resistor in parallel with the $1 \mathrm{k}$-ohm zero control reduces the control's sensitivity. A 1-megohm potentiometer in the feedback loop adjusts the gain of the amplifier. The meter amplifier (upper right-hand corner, Fig. 4) is a fixed gain inverting amplifier. The $10 \mathrm{k}$ ohm dc offset potentiometer was adjusted for a $0-\mathrm{m}$ output reading, with Pin 7 grounded via a $10 \mathrm{k}$-ohm resistor. Three ranges of sensitivity are provided by the three resistors which are switched in series with the milliammeter. A dc output jack allows the unit to be used with a chart recorder when permanent records are required.

An integrating amplifier circuit (lower right-hand corner, Fig. 4) is switched into the meter circuit when the function switch (S4) is in the integrate mode (Int). This circuit has a de output proportional to the time integral of the input

$$
E_{\text {out }}+-\frac{1}{\mathrm{RC}} \int^{+} \mathrm{E}_{\text {in }} \mathrm{df}
$$

tensile testing instrument through a 4-mm-diam solid metal cylinder centered on the bite plate, $1 \mathrm{~mm}$ from the end of the positioning arm. It was originally intended to have the meter read out directly in pounds force; however, it was found that bite elements could not be easily built with a linear force-output function. Furthermore, each bite element displayed a different force-output function, making the use of nonlinear amplifiers impractical. Calibration charts were thus made for each bite element (Fig. 5); this allows the user to convert the gnathodynamometer's meter reading into force values. It was found after repeated calibration checks with known force values that an accuracy of $\pm 3 \mathrm{lb}$ could be expected. Long-term accuracy is made possible by periodically checking the "zero" and "gain" controls for a zero and full-scale reading. The proper adjustment of these controls compensates for variation in battery voltages. It should be noted that this instrument, as well as earlier devices described above, measures pounds of force applied between two surfaces, not pressure. Pressure is a measure of a force exerted per unit area, with the most common unit being the square inch (psi). Pounds of force measurements are made without reference to area.

Tests of the gnathodynamometer's ability to integrate force over time were made using the same tensile testing instrument. Specific forces were applied over a varied time interval. It was found that the gnathodynamometer did in fact integrate force over time and did so in a linear manner, i.e., $20 \mathrm{lb}$ force for 5 sec produced a meter reading of .10, whereas $20 \mathrm{lb}$ force for $10 \mathrm{sec}$ produced a meter reading of .20 . Note that in using the integrate mode the same meter reading may be produced

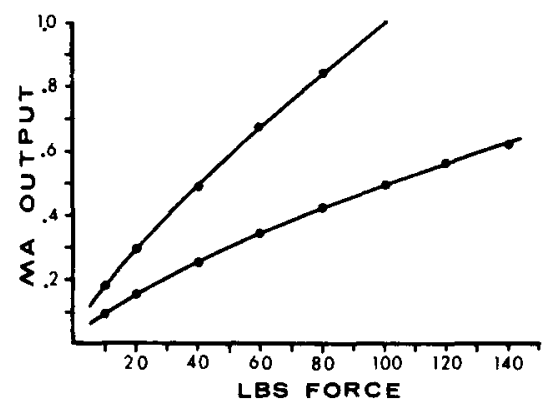

Fig. 5. Sample calibration chart for gnathodynamometer bite element used in converting milliammeter output to pounds biting force. The upper curve is used for the X50 scale and the lower curve is used on the X100 scale. 


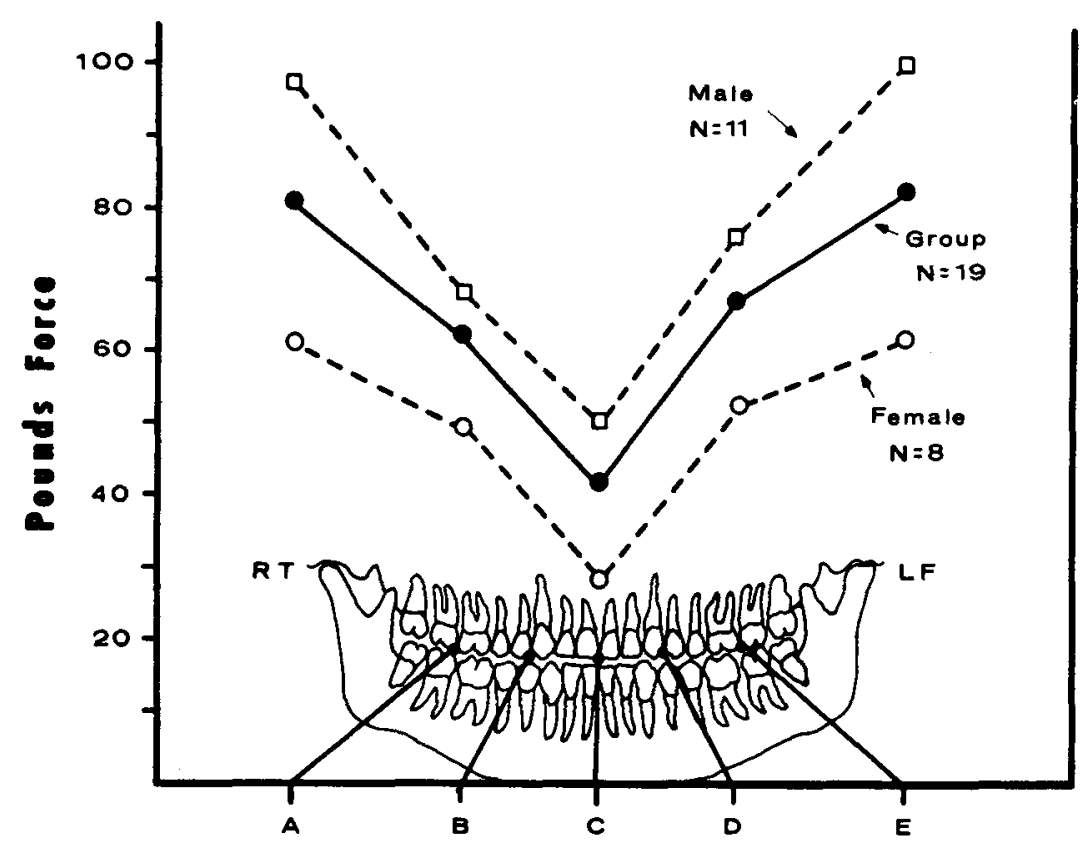

Test Position

Fig. 6. Mean biting forces as a function of five test positions and sex as measured with the gnathodynamometer described in the text. The bite element positioning arm was used to determine exact placement between $S$ s by positioning the arm into the outer cleavage of the upper teeth at each test point.

in numerous ways. For example, a reading of .80 may be produced by a force of $10 \mathrm{lb}$ applied for $80 \mathrm{sec}, 20 \mathrm{lb}$ for $40 \mathrm{sec}$, or $40 \mathrm{lb}$ for $20 \mathrm{sec}$, etc. When long-term drift was compensated for by adjustment of the "zero" control, integrated force measures were repeatable to $\pm 2 \%$ of the meter reading.

\section{Operating Characteristics and Discussion}

The instrument described above was designed to fill the need for a portable, inexpensive gnathodynamometer with a very thin bite element. A thin bite element was felt desirable to closely approximate the vertical jaw relationship during chewing, swallowing, and bruxing. Materials for the instrument cost about $\$ 60$. Battery life was found to be $60 \mathrm{~h}$. A nonportable unit for use on $110-\mathrm{V}$ ac power could be built using commercial dc power supplies if portability was not required. Except for battery replacements, no component failures have occurred.

The instrument has been used in our laboratory to calibrate other instruments designed to investigate human chewing behavior (Rugh, 1971) and to measure biting forces in normal and pathologic populations. Data presented in Fig. 6 are an example of data collected using the gnathodynamometer. Maximum biting forces of 19 healthy adults were recorded at five different positions of the mouth. Sex differences in this sample are apparent; male force values were consistently greater than those of the female. Klatsky (1942) reported finding similar sex differences. Comparison between studies reporting maximum human biting forces must be made cautiously because the measurements are typically made using different apparatuses, procedures, and populations. Brawley and Sedwick (1940) reviewed 27 studies which reported maximum biting force values ranging from 45 to $550 \mathrm{lb}$ in adult populations. Too frequently these reports lack any description of the instrument used. Future reports of biting forces obtained using the above or any other gnathodynamometer should be accompanied by a detailed description of the bite element employed. Further discussion of the problems and applications of gnathodynamometers may be found in reviews by Haber (1929), Klaffenback (1936), O'Rourke (1949), and Lawson (1960).

\section{RE FERENCES}

ANDERSON, D. J. Measurement of stress in mastication. Journal of Dental Research $1956,35,664-673$.

BLACK, G. V. The force exerted in the closure of the jaws. Dental Cosmos, 1895. $6,469.484$

BOONE, M. E. The effect of a denture reline and a denture stabilizer upon the biting force of complete denture wearers. Thesis, Indiana University School of Dentistry, 1962.

BOOS, R. H. Intermaxillary relation established by biting power. Journal of the American Dental Association, 1940 27, 1192-1199.

BOUCHER, L. J., ZWENER, T. J., \& PFLUGHOEET, F. Can biting force be used as a criterion for registering vertical dimension? Journal of Prosthetic Dentistry, 1959, 9, 594-599.

BOWMAN, A. Flexion of the mandible. Thesis, Indiana University School of Dentistry, 1970

BRAWLEY, R. E., \& SEDWICK, H. J Studies concerning the oral cavity and saliva. II. Biting pressure. American Joumal of Orthodontics, 1940, 26, 41.

HABER, G. The gnatho dynamometer in stomatologic practice. American Dental Surgeon, 1929, 49, 551.

HOWELL, A. H. \& BRUDEVOLD, F. Vertical forces used during chewing of food. Journal of Dental Research, 1950 29, 133-136.

HOWELL, A. H \& MNLY, $R$, An electronic strain gauge for measuring orgl forces. Journal of Dental Research, 1948 , 27,705 .

JOHNSON, A. L. \& HATFIELD, H. K. A study of the relation of dental conditions, biting force, and the hand-grip. Dental Cosmos, 1917, 59, 599-609.

KLAFFEN BACK, A. O. Gnathodynamics. Journal of the American Dental Association, 1936, 23, 371-382.

KLATSKY, $\dot{M}$. Masticatory stresses and their relation to dental caries. Journal of Dental Research, 1942, 21, 389

LAWSON, W. A. The validity of a method used for measuring masticatory forces. Journal of Prosthetic Dentistry, 1960, 10 99

O'ROURKE, J. T. Significance of tests for biting strength. Journal of the American Dental Association, 1949, 38, 10,99.

RUGH, J. D. A telemetry system for measuring chewing behavior in humans. Behavior Research Methods Instrumentation, 1971, 3, 73-77.

SCOTT, 1. S., \& ASH, M. M. Micro miniature intraoral telemetry system. Proceedings of the International Telem etering Conference, October 1970. VAIL, G. H. The development and use of an intraoral force transducer in the diagnosis and treatment of myasthenia gravis. Thesis, Indiana University School of Dentistry, 1970 